\title{
A cultura do outro em Histórias de leves enganos e parecenças, de Conceição Evaristo
}

\author{
Nivana Ferreira da Silva ${ }^{1}$
}

\section{Notas introdutórias: estudos culturais e o cânone literário}

A expansão da cultura e sua centralidade, além do reconhecimento de sua importância para o entendimento das relações e das instituições sociais, caracterizam a chamada "virada cultural" (Hall, 1997, p. 27), quando foram ampliadas as compreensões em torno da linguagem - até então concebida como responsável por apenas relatar os fatos e não como constitutiva desses - e houve um repensar a cultura, considerando seu caráter fundamental, e não simplesmente dependente, para a vida social. Nesse cenário, o surgimento do campo interdisciplinar dos estudos culturais representou (e vem representando) a possibilidade de abordarmos a cultura sob um espectro mais amplo, tratando das heterogeneidades culturais, da construção de identidades e agenciamentos, da análise da cultura que foi legitimada e daquela que foi colocada à margem, do questionamento das hierarquias, em suma, da reflexão sobre como as produções culturais são formatadas e operam nas diversas sociedades.

Inevitavelmente, a literatura, considerada uma prática cultural específica, não escapa ao que abarcam os estudos culturais, cujo projeto, diga-se de passagem, vem se redesenhando e se reconfigurando desde o seu surgimento, independentemente da narrativa de origem que lhe dê sustentação. ${ }^{2}$ Durante muito tempo, grupos marginalizados na sociedade também estiveram excluídos do âmbito literário, seja enquanto autores, seja no modo como foram representados, com suas diferenças e vozes, no mais das vezes, apagadas e silenciadas. $\mathrm{O}$ horizonte de abrangência dos estudos culturais, que permite pensar como uma cultura hegemônica se

\footnotetext{
${ }^{1}$ Doutoranda do Programa de Pós-Graduação em Literatura e Cultura da Universidade Federal da Bahia (UFBA), Salvador, BA, Brasil. E-mail: nivanafs@ hotmail.com

2 Ana Carolina Escosteguy (2010, p. 30), atentando para a complexidade que envolve os estudos culturais, considera a existência de mais de uma narrativa para a fundação do campo, para além da canônica versão britânica. A autora pondera: "Em contraposição a essa versão dominante, afirma-se que em outras localidades e em outros momentos podem ser identificadas 'outras' origens para esse campo de estudos" e concentra seu trabalho, especificamente, nos estudos culturais latinoamericanos.
} 
estabeleceu como tal e se colocou como central, possibilita, de igual modo, problematizar a constituição do cânone literário, ideologicamente concebido e voltado para o valor de "grandes obras".

Diante do conceito de representação, tão caro à teoria literária, emergem alguns questionamentos iniciais, relevantes para a nossa reflexão, quais sejam: Quem o cânone representa? Como ele é formado? O que ele deixa à margem e por quê? Sabemos que a marginalização cultural decorre, entre outros fatores, de exclusões sociais e de apagamentos de diferenças e características locais, comumente suplantadas pela ideia de global, que nada mais é do que um modelo local tomado como universal e hegemônico devido a circunstâncias, valores e interesses específicos. No caso da literatura, a institucionalização de referências canônicas aponta para um conjunto de hierarquias e de escolhas, relacionado a processos de exclusões, que acabam refletindo a distribuição desigual e secular dos poderes na sociedade e os privilégios das elites econômicas e intelectuais. Nesse contexto, é exemplar, e não por acaso, a ausência no cânone, durante muito tempo, das mulheres e dos negros e, duplamente invisibilizadas, das mulheres negras.

Particularmente no que diz respeito à questão racial, o próprio sistema mediático, no qual, além dos jornais e das agências publicitárias, estão incluídas as editoras, constitui-se, tradicionalmente, de elites intelectuais, funcionando "como filtro e síntese de variadas formas de ação e cognição presentes nas elites econômicas, políticas e culturais coexistentes num contexto social" (Sodré, 2000, p. 244). Sob essa perspectiva, Muniz Sodré fala em "racismo mediático" (p. 245), suscitado pelos seguintes fatores: negação, recalcamento, estigmatização e indiferença profissional, ou seja, a grande mídia tende a negar que o racismo exista - a menos quando esse é objeto noticioso -, assim como recalcar características positivas das manifestações de origem negra. "O mesmo acontece quando se trata de vultos importantes da história, das artes, da literatura" (Sodré, 2000, p. 245). Ademais, há uma desvalorização da diferença e atribuição de estigma àqueles que não pertencem aos grupos brancos e uma parca presença de negros como profissionais ocupando funções importantes da indústria cultural brasileira.

Já no tocante ao gênero, a exclusão da mulher do cânone enquanto autoras bem como a representação feminina dada por meio de estereótipos corresponderam à lógica falocêntrica de dominação e aos valores patriarcais que imperaram na sociedade. Reafirmamos que, mais 
à margem ainda, esteve a mulher negra, pois, além dessa conjuntura sexista, o estigma da cor, consequência de um discurso racista estrutural e congênito, impulsionou seu apagamento da esfera literária, quando não fez recrudescer a presença de personagens folclorizadas e erotizadas.

Partindo do tema sobre a formação do cânone, com seus desdobramentos relativos às questões raciais e de gênero, a reflexão que aqui se insere visa levantar uma discussão sobre a exclusão da mulher negra na literatura, fundamentada em um arcabouço teórico-crítico pertencente à esfera dos estudos culturais, devido às possibilidades que o campo oferece para a já mencionada problematização sobre como uma cultura hegemônica se configurou desse modo. Esse debate, por sua vez, pode ser levado para o tratamento do legitimado modelo literário canônico e os processos de hierarquizações e escolhas resultantes de um conjunto maior de práticas sociais. Haja vista o interesse pela literatura feminina de autoria negra, trazemos à baila o trabalho da escritora mineira Conceição Evaristo, com seu livro Histórias de leves enganos e parecenças (2016), objeto cultural emblemático para a reflexão almejada.

\section{Questões raciais e de gênero na literatura}

Os estudos culturais trazem novos questionamentos para o contexto literário, ao passo que reformulam alguns já existentes, porquanto abrem espaço para pensarmos outros significados e outras representações. O caráter interdisciplinar do campo alarga o diálogo da literatura enquanto prática cultural, com variados discursos e áreas do conhecimento, possibilitando, por exemplo, o entendimento das interseções entre a tradição literária, as imposições ligadas à cultura, os mecanismos de poder por detrás das relações e instituições sociais, além dos lugares de referência e opressão para os grupos minorados.

Entender como uma cultura se impôs (e se impõe) sobre outras reclama pelo reconhecimento, não apenas das colonizações e dominações territoriais e humanas, mas da subalternização histórica do conhecimento. As modernidades coloniais, construídas sob histórias locais hegemônicas, formataram projetos globais e impuseram modelos universais de cultura, sociedade e ciência, fomentando a chamada colonialidade do poder, cujo exercício se deu, em um primeiro momento, nos Estados coloniais e, em seguida, após 
os processos de independência, nos Estados-Nação, engendrando uma espécie de colonialismo interno (Mignolo, 2003).

Nessa direção, cabe também reconhecer a existência de uma pluralidade de saberes, para além do saber hegemônico da cultura ocidental e da ciência moderna, que, conforme Boaventura Santos (2008), constitui uma forma privilegiada - com privilégios extracognitivos, pois engloba aspectos políticos, sociais e culturais - de conhecimento. Logo, "o reconhecimento da diversidade epistemológica do mundo sugere que a diversidade é também cultural e, em última instância, ontológica, traduzindo-se em múltiplas concepções de ser e estar no mundo" (Santos, 2008, p. 142).

Diante desse reconhecimento, é inegável o papel significativo da crítica pós-moderna, ao colocar em xeque a lógica de dominação, os estatutos das verdades absolutas, a naturalização das categorias e a ideia de origem. No entanto, esse discurso se ancora nas margens internas do problema, ou seja, diz respeito a "uma crítica eurocêntrica ao eurocentrismo" (Mignolo, 2003 p. 422) e, por isso, distancia-se da compreensão em torno da diferença epistêmica colonial, que "implica pensar a partir de um outro lugar, imaginar uma outra língua, argumentar a partir de uma outra lógica. Os pensadores canônicos do cânone ocidental não mais podem oferecer um ponto de partida para a epistemologia exigida pela diferença colonial" (Mignolo, 2003, p. 422).

Em outras palavras, Walter Mignolo advoga por uma crítica que problematize a subalternização dos saberes e as hierarquizações epistemológicas, apoiada no próprio conhecimento do subalterno e das minorias, o que viabilizaria a emergência de histórias, de culturas e de vozes silenciadas e não legitimadas. Desse modo, segundo o autor, "é crucial transcender a diferença colonial epistemológica, tendo no pensamento liminar uma forma de fazê-lo, uma vez que compreendamos que os esplendores das ciências ocidentais são inseparáveis de suas misérias" (Mignolo, 2003, p. 425). Sob essa ótica, é interessante, na argumentação de Mignolo, o exemplo sobre as feministas pós-modernas, que, segundo ele, criticam apenas a episteme masculina, diferentemente das feministas do Terceiro Mundo e das mulheres de cor, que, além de questionar a supremacia do falo, também se posicionam contrariamente à epistemologia branca.

Podemos afirmar que as reflexões de Bell Hooks (2014) vão nesse sentido, pois se trata de uma ativista feminista negra. Assim, 
considerando a perspectiva apontada, a intelectual estadunidense transcende a diferença colonial epistemológica a partir do pensamento liminar. Seus posicionamentos defendem que não há equivalência e unidade no estatuto social da mulher, de um modo geral, afinal de contas, nem todas "são igualmente oprimidas, porque algumas mulheres podem usar a sua classe, raça e privilégios educacionais para resistirem à opressão sexista" (Hooks, 2014, p. 104).

No cerne dessa discussão, relembremos que os movimentos feministas do século XIX visavam igualdade de gênero para as mulheres brancas, embora o discurso estivesse velado por um comprometimento com o grupo feminino como um todo. O racismo, ainda que disfarçado, sobrepunha-se à luta pelos direitos iguais, pois era conveniente, de certa maneira, que as brancas mantivessem uma hierarquia sobre as negras como uma forma de esboroar a então situação inferior em relação aos homens. Segundo Bell Hooks:

Os preconceitos que a mulheres brancas ativistas sentiam em relação às mulheres negras eram de longe mais intensos que os seus preconceitos em relação aos homens negros. [...]. As atitudes negativas em relação às mulheres negras foram o resultado da prevalência de estereótipos racistas-sexistas que retratavam as mulheres negras como moralmente impuras. Muitas mulheres brancas sentiam que o seu estatuto de senhoras podia ser minado se elas se associassem às mulheres negras. [...]. Dado o medo branco da fusão de raças e a história da luxúria dos homens brancos sobre as mulheres negras, não podemos deixar de fora a possibilidade que as mulheres brancas estavam relutantes em reconhecer socialmente as mulheres negras por medo de competição sexual (Hooks, 2014, p. 94-95).

O mesmo movimento feminista que, na teoria, salientemos, ergueu a bandeira pela igualdade de gêneros em sentido lato e plural, não reconheceu socialmente as mulheres negras, posicionou-se contra $o$ sufrágio dos homens negros e propagou um discurso que estava apenas fundamentado no caráter sexista do problema, ignorando a questão racial e os privilégios de classe. Isso evidencia uma enraizada história de exploração e de racismo, que não se restringe apenas à narrativa norteamericana de Bell Hooks, mas aparece também, de modo bastante marcante e complexo, na sociedade brasileira, em que o grupo branco se 
colocou como padrão de referência, fortalecendo seu autoconceito e legitimando sua supremacia econômica, política e social.

A discriminação racial, portanto, é um dos motes para a manutenção dos privilégios e conquistas de um grupo sobre o outro, gerando opressões, tanto materiais, quanto simbólicas (Bento, 2014). Esse segundo caso ocorre comumente na literatura, em que discursos culturalmente valorizados representam e marginalizam grupos sociais específicos. Alicerçados nesse ponto de vista, e citando especificamente o grupo feminino, observamos que a inclusão da mulher branca no campo literário difere do mesmo processo para a mulher negra, seja como autoras, seja como personagens, não deixando de revelar o problema maior da pequena expressão, quando não da ausência, da população negra nos espaços discursivos e de poder.

Sabemos que a predominância masculina na literatura afastou por muito tempo a mulher da esfera criadora e refletiu a organização patriarcal da sociedade, conjuntura duplamente sublinhada para a mulher negra, pois, nesse caso, o critério racial coaduna-se com o de gênero. Para além da autoria, as representações femininas acionadas geralmente apresentam, de um lado, as heroínas brancas e, de outro, as personagens estereotipadas negras, retratadas por diversos autores homens, independentemente de sua cor. Esse aspecto aponta para a seguinte reflexão de Bell Hooks:

Para manter a estrutura de apartheid que a escravatura institucionalizou, os colonizadores brancos, masculinos e femininos, criaram uma variedade de mitos e estereótipos para diferenciar o estatuto das mulheres negras das mulheres brancas. Os racistas brancos, e ainda alguns negros que absorveram a mentalidade do colonizador descreveram a mulher branca como símbolo de perfeita natureza feminina e encorajaram as mulheres negras para se esforçarem para atingir tal perfeição usando a mulher branca como modelo (Hooks, 2014, p. 111).

Esse processo descrito pela autora, foi muito recorrente, quase uma regra, por um longo período, em artigos de jornais, anúncios e livros, consolidando um determinado modelo de representação em detrimento de outros. Trata-se do que Guerreiro Ramos (1995, p. 215) chamou de "negro-tema", isto é, a forma como os negros (e negras) foram retratados por literatos e outros estudiosos enquanto "uma coisa examinada, olhada, vista, ora como ser mumificado, ora como ser curioso, ou de qualquer 
modo como um risco, um traço da realidade nacional que chama atenção" (Ramos, 1995, p. 215), o que deixa em evidência o caráter dominante da brancura como "critério de estética social" (p. 216).

Sendo assim, a cultura branca se impôs e se instituiu como paradigma, um lugar de referência, até mesmo para o negro, o que configurou, de acordo com a definição de Maria Aparecida Bento (2014, p. 30), "um forte componente narcísico, de autopreservação, porque vem acompanhado de um pesado investimento na colocação desse grupo como grupo de referência da condição humana". Esse componente narcísico reitera o caráter político e ideológico do estrutural problema do branqueamento que, na literatura, ganha também o matiz estético. Na contemporaneidade, além da minguada presença de personagens negros, o tema racial aparece nos romances - na maioria das vezes e quando aparece - marcado por estigmas e exclusões. Mais reduzido ainda é o número de mulheres negras representadas enquanto protagonistas e narradoras, havendo, nesses casos, a predominância de homens brancos. ${ }^{3}$

O problema que então se coloca "não é o de uma imitação imperfeita do mundo, mas a invisibilização de grupos sociais inteiros e o silenciamento de inúmeras perspectivas sociais, como as dos negros" (Dalcastagnè, 2008, p. 89). Por essa razão, há um impasse para que os grupos marginalizados se identifiquem com uma cultura imposta, embora a força da hegemonia faça com que modelos colocados como ideais se estabeleçam e se fixem como paradigmas para as minorias, conforme dito anteriormente.

Todavia, existem exceções a essa regra. Ao se referir às duas formas de racismo, racismo aberto e racismo disfarçado (ou por denegação), Lélia Gonzalez (1988) considera que o primeiro, embora possa culminar em formas de segregação explícita, tende a reforçar a identidade racial dos negros e impulsionar sua produção científica e literária, uma vez que as práticas cruéis do sistema são reconhecidas e, nesse sentido, o grupo se une contra a opressão racista. Já no racismo disfarçado, o das nossas sociedades, como ressalta a autora, "a força cultural apresenta-se como a melhor forma de resistência. $\mathrm{O}$

\footnotetext{
${ }^{3}$ Referência aos dados da pesquisa quantitativa sobre o romance brasileiro dos últimos anos, cuja proposta é "entender o que o romance brasileiro recente - aquele que passa pelo filtro das grandes editoras, atinge um público mais amplo e influencia novas gerações de escritores - está escolhendo como foco de seu interesse, o que está deixando de fora e, enfim, como está trabalhando as questões raciais" (Dalcastagnè, 2008, p. 89).
} 
que não significa que vozes solitárias não se ergam, efetuando análises/denúncias do sistema vigente" (Gonzalez, 1988, p. 74).

A força cultural, como resistência e como embate à perpetuação do preconceito no interior do discurso literário, pode ser observada quando representantes das minorias passam a ser sujeitos de suas enunciações, enquanto autoras e autores, e objetos de suas próprias narrativas, como ocorre na literatura de autoria negra. Carolina Maria de Jesus é um exemplo clássico nesse cenário. Semianalfabeta, favelada e negra, legou Quarto de despejo (1963), sua obra mais conhecida, e foi de encontro às normas sociais da época. Na literatura contemporânea brasileira, encontramos a produção teórica e literária de Conceição Evaristo, cuja assinatura autoral faz ecoar as vozes das margens, contrapondo-se às representações literárias já estabelecidas e endossando um não pertencimento ao cânone, cujo território frequentemente inviabilizou os agenciamentos das vivências legítimas (mas não legitimadas) das mulheres negras. A obra evaristiana, portanto, é expressiva para a discussão em tela, na medida em que possibilita o questionamento da tradição cultural hegemônica e nos leva ao reconhecimento de outras identidades, bem como de outras perspectivas sociais e suas formas de representação.

\section{Histórias de leves enganos e parecenças: o debate contemporâneo de Conceição Evaristo}

Consideramos que Conceição Evaristo imprime sua marca autoral no espaço intercultural do "atlântico negro" (Gilroy, 2001, p. 33), unidade de análise e chave teórico-metodológica, na qual emergem "formas culturais estereofônicas, bilíngues ou bifocais originadas pelos - mas não propriedade exclusiva dos - negros dispersos nas estruturas de sentimento, produção, comunicação e memória" (p. 35). Lançamos mão desse argumento, pois a escritora mineira apropria-se, em sua obra, de traços, de significados e de ancestralidades africanas, reinscrevendo-os em outros contextos, sem limitar-se, evidentemente, a um absolutismo ou fechamento étnico. Para Paul Gilroy, os negros ocidentais estão em pelo menos dois grandes grupos culturais, o que diz respeito a não existência de uma ideia unitária de comunidade negra e às características polifônicas de suas expressões culturais. 
No mais recente livro de Evaristo, Histórias de leves enganos e parecenças (2016), lançado pela editora carioca Malê, filiações com uma ancestralidade de matriz africana e afro-brasileira são desveladas, consolidando marcas da oralidade e da memória, individual e coletiva características que podemos associar à assinatura autoral da escritora mineira - e reafirmando a constituição de identidades plurais em um espaço intercultural, sem particularismos étnicos e culturais. Os doze contos e a novela que compõem a obra são perpassados por nuances de mistério, traços de encantamento e elementos do insólito, aproximandose, conforme definição da professora Assunção Sousa e Silva, no prefácio que acompanha a obra, de um

realismo animista (termo cunhado pelo escritor angolano Pepetela), perspectivado em diversas narrativas africanas. Isso porque a existência da atuação de forças da natureza, da alteração dos fenômenos que modificam a ordem natural das coisas, a crença em entidades capazes de intervir na rotina dos personagens etc. são estratégias concebidas por um modus operandi revelador da maneira de pensar, de ser e de existir de uma dada comunidade cujas origens advêm da diáspora africana (Silva, 2016, p. 8).

Esse modus operandi, revelador das origens africanas, articula-se com algumas facetas da realidade brasileira, como as disparidades sociais, a violência diária contra jovens de classes sociais menos favorecidas, a questão das favelas nas localidades urbanas e o sincretismo religioso. Em "Os guris de Dolores Feliciana", a personagem-mãe que dá título ao conto tem os três filhos assassinados e, fortemente abalada, vertia lágrimas de sangue, aplacadas em certa medida pelo constante retorno e presença dos meninos. Dolores Feliciana teve sua foto publicada em um periódico que a comparou a "Mater dolorosa", despertando a fúria de outro jornal, pois "a dor de uma mãe qualquer" não poderia ser comparada "com a dor da Mãe de Cristo, nosso Salvador" (Evaristo, 2016, p. 47).

A discriminação social, indissociável do preconceito racial, pois "a pobreza tem cor, [...] mas não é conveniente considerá-la" (Bento, 2014, p. 27), também é visível em "Mansões e puxadinhos", narrativa que reafirma o contraste entre os barracos do morro e os grandes casarões, os quais "abrigavam luxuosamente famílias com histórias de poder e abuso em seus círculos" (Evaristo, 2016, p. 53). A geografia contrastante da região descrita no conto foi contornada algumas vezes por "um odor maléfico desconsertando a todos. Festas foram muitas vezes 
interrompidas, pois os convidados, apesar das regras de etiqueta, se retiravam antes mesmo dos banquetes serem servidos, em estado de quase sufocamento pela podridão do ar" (p. 53). Não se sabia ao certo de onde vinha o tal odor, até que um dia

a exalação malcheirosa irrompeu repentinamente o ar e veio acrescida de outro elemento, uma pesada nuvem de fumaça. [...] Os das mansões mobilizaram repórteres, políticos, cientistas (mais uma vez), na vã tentativa de parar o acontecido. Os dos puxadinhos movimentaram seus santos, suas orações de fé, seus temores diante do inexplicável e a certeza de que alguma coisa precisava ser feita. [...] [Os habitantes da mansão] resolveram contratar pessoas para explorarem a área. Porém, como eles já haviam gasto verbas e mais verbas com os cientistas, decidiram usar os trabalhadores locais, aqueles que já tinham funções junto a eles. [...] E antes mesmo de chegarem na metade da expedição recuaram e informaram aos das mansões que não tinham encontrado nada, a não ser a moradia deles próprios. A guerra então foi declarada e a culpa imputada à população dos puxadinhos (Evaristo, 2016, p. 56- 57).

Apesar do caráter fantasioso e imprevisível da história, há nela dois elementos relacionados ao preconceito racial que ultrapassam o plano simbólico. O primeiro deles é a construção de um imaginário negativo sobre o negro, o que muitas vezes levou a sua culpabilização, como no caso das epidemias que assolaram a Europa nos séculos XVI e XVII, em que os culpados potenciais "estavam em primeiro plano na vizinhança, nas aldeias próximas ou entre clãs rivais, no interior de uma mesma localidade" (Bento, 2014, p. 33), consequência do medo - segundo elemento - que as elites sempre tiveram dos povos marginalizados, colocados como uma ameaça à manutenção de seus privilégios. $\mathrm{O}$ medo não deixa de estar associado ao "ódio narcísico", que, ainda segundo Bento (2014, p. 38), "é explicado por Adorno e Horkheimer (1985) pela paranoia, também pautada nas defesas primitivas em que se expulsa tudo o que possa representar uma ameaça à autopreservação egoica".

O tema religioso aparece no conto "A moça de vestido amarelo", em que Dóris da Conceição Aparecida, prestes a fazer a primeira comunhão, sonhou com uma mulher de traje amarelo, cor que, desde a primeira infância, sempre esteve presente nas falas e nas ações da menina. Para sua família, a tal mulher do sonho só "poderia ser a 
Nossa Senhora dos Católicos" (Evaristo, 2016, p. 24), apesar de apenas a avó de Dóris entender o motivo daquela referência, "guardada no inconsciente" da neta. Na hora da comunhão, uma surpresa: "a menina ao invés de rezar a Ave-Maria, oração ensaiada por tanto tempo, cantou outro cumprimento. Cantou e dançou como se tocasse suavemente as águas serenas de um rio. Alguns entenderam a nova celebração que ali aconteceu" (Evaristo, 2016, p. 25). Na narrativa, a fé católica hegemônica, imposta a outras culturas durante séculos, dá lugar a uma identificação da personagem com suas verdadeiras raízes, as quais apenas a matriarca, sua avó, reconhecia e entendia. A questão da fé e do sincretismo religioso também está presente em "Nossa senhora das Luminescências", santa cuja presença "é tão confortante que a pessoa recorda que essa vida terrena é apenas tempo de preparação para outra vida" (Evaristo, 2016, p. 36).

É interessante notar que, em sua maioria, as narrativas giram em torno de mulheres - crianças, moças ou mães - protagonistas de suas vivências, que contam e escutam histórias passadas de geração em geração, fazendo emergir o fantástico e o imprevisível a partir de uma mescla entre a tradição e o contemporâneo. Chama atenção o não tão sutil jogo entre os nomes próprios de algumas delas e seus respectivos enredos, a exemplo de Rosa Maria Rosa, do conto homônimo, cujas axilas gotejavam pétalas de flores; Fémina Jasmine, de "A menina e a gravata", e sua imensa predileção, desde pequena, por essa peça do vestuário masculino, especialmente as de formato borboleta, que com ela "fazia profundos voos" (Evaristo, 2016, p. 27); ou a personagem que dá título ao conto "Inguitinha", que "parecia caber no fragmento 'inha'" em tudo o que fazia" (Evaristo, 2016, p. 19). A brincadeira com as alcunhas acontece também em "Os pés do dançarino", em que o rapaz Davenir, por ter ignorado suas origens quando ganha fama, "deu pela ausência dos pés" e precisava "fazer o caminho de volta", profecia da Bisa, "a mais velha das velhas" (Evaristo, 2016, p. 44).

Tal como a Bisa, a presença de mulheres sábias, vigorosas e disseminadoras de crenças e valores de suas culturas é recorrente na antologia e tem seu ponto alto em "Sabela". A novela, dividida em três partes, apresenta histórias entrelaçadas a um acontecimento maior, um dilúvio - que, diga-se de passagem, não tem ancoragem bíblica, tampouco culmina com uma grande arca - previsto e, literalmente, sentido por uma sábia senhora-mãe, que dá nome a história, por sua vez 
reconstruída pela filha, também Sabela, e pelos sobreviventes da singular tragédia, na qual vemos "grandes e pequenos se igualando no insulto das águas" (Evaristo, 2016, p. 97). Apresentando a origem dos povos habitantes do lugar, a narradora descreve:

Levantamentos parecidos já haviam sido feitos com algumas famílias tradicionais da cidade. Os lindorgalienses tinham vindo de uma localidade chamada Lindorgália, os beneventes de Benevuta, os darlinguenses de Darling, os goldenses de Gold. As ancestrais de Sabela haviam nascido em algum lugar, uma terra que poderia ser: Mambela, Zimbela, Kumbela, Umbela... [...]. Povos que tinham vindo pelos caminhos das águas. Corria a história, de que as águas salgadas do mar, no momento em que esses povos, por vários motivos, faziam uma forçada travessia, gemiam sons dolorosos, como se fossem humanos lamentos. [...] Na periferia da cidade, em que viviam Vovó Sabela e Mamãe, havia um povo que era esquecido por todos. Eram os Palavís. Povos que, desde sempre, habitavam, não só, aquele sítio, mas todo o território. Eram os povos primeiros. Porém, com a chegada dos lindorgalienses, dos benevutos e de outros, os Palavís foram confinando cada vez mais nas terras que margeavam a cidade (Evaristo, 2016, p. 66 e 67).

Aqui, para a além do jogo com os nomes próprios, a referência indireta à diáspora africana e à exploração aos índios, "os povos primeiros", insere-se de modo inusitado, mas não menos contundente e até mesmo irônico, trazendo, de algum modo, a reflexão em torno das consequências do tráfico negreiro e da dominação colonial. Em "Sabela", assim como nos contos "O sagrado pão dos filhos", "Fios de ouro" e no já referido "A moça de vestido amarelo", as narradoras recompõem, contam e revivem memórias, mitos e rituais, reafirmando tradições familiares femininas muito fortes e passando adiante suas escrevivências, ou seja, "textos que nós mulheres e homens negros criamos", segundo definição de Conceição Evaristo. ${ }^{4}$ A palavra em itálico, presente como uma marca do trabalho teórico e literário da escritora mineira, pode ser associada, também, às histórias transmitidas pelas mulheres de sua família, fonte e fundamento para sua escrita, conforme relata:

\footnotetext{
${ }^{4}$ Conforme fala da autora na última edição da Festa Literária Internacional de Cachoeira - Flica, em 2016, na mesa "As águas dos contrassonetos e os olhos da vândala insubmissão". Disponível em: 〈https://goo.gl/Px35Jw>. Acesso em: 3 nov. 2016.
} 
Foram elas [as mãos lavadeiras de sua mãe] que guiaram os meus dedos no exercício de copiar meu nome, as letras do alfabeto, as sílabas, os números, difíceis deveres de escola, para crianças oriundas de famílias semianalfabetas. [...] creio que a gênese de minha escrita está no acumulo de tudo que ouvi desde a infância. $\mathrm{O}$ acúmulo das palavras, das histórias que habitavam em nossa casa e adjacências. Dos fatos contados a meia-voz, dos relatos da noite, segredos, histórias que as crianças não podiam ouvir. [...] Como ouvi conversas de mulheres! Falar e ouvir entre nós, era a talvez a única defesa, o único remédio que possuíamos. Venho de uma família em que as mulheres, mesmo não estando totalmente livres de uma dominação machista, primeiro a dos patrões, depois a dos homens seus familiares, raramente se permitiam fragilizar. Consciência que compromete a minha escrita como um lugar de autoafirmação de minhas particularidades, de minhas especificidades como sujeito-mulher-negra (Evaristo, 2007, p. 18).

As histórias ouvidas pela autora, desde a sua infância, e o legado deixado por sua mãe e pelas mulheres de sua família contribuíram para a formação de suas experiências, valores e identidades, em suma, de sua escrevivência, caracterizada pela biografia das mulheres negras na sociedade brasileira, ${ }^{5}$ algo que está comprometido com o trabalho da ficção, com histórias ficcionalizadas. Encontramos esse registro em Histórias de leves enganos e parecenças, que não deixa de inscrever a herança da dominação, não só patriarcal, mas também escravocrata, as relações de poder, as pluralidades identitárias e o questionamento das hierarquias, sempre sob uma leveza onírica e imprevisível, mas sem deixar de agenciar um compromisso com a resistência e com a solidariedade feminina negra - a consciência que compromete sua escrita como lugar de autoafirmação -, afinal, trata-se de construir uma assinatura por meio das escrevivências que não podem ser lidas "como histórias para 'ninar os da casa grande' e sim para incomodá-los em seus sonos injustos" (Evaristo, 2007, p. 21).

\section{Considerações finais}

Podemos afirmar que as inserções e as supressões de vozes, de modelos e de identidades na esfera cultural são consequência da

\footnotetext{
${ }^{5}$ Segundo afirmação de Evaristo, na mesma ocasião da Flica (ver nota 4).
} 
distribuição desigual de poderes e de privilégios, comumente concentrados nas mãos das elites intelectuais e econômicas. Particularmente na constituição do cânone literário, há toda uma dinâmica de hierarquias e de escolhas que, de maneira inevitável, culmina em - e também é resultado de - processos de exclusões, silenciamentos e marginalizações de grupos sociais com suas linguagens e representações.

Diante desse contexto, a produção cultural de Conceição Evaristo em Histórias de leves enganos e parecenças não deixa de se contrapor, além de ser uma forma de resistência, à tradição literária hegemônica, já que representantes das minorias - mulheres, sobretudo -, ora enquanto narradoras, ora como personagens de suas vivências, agenciam suas narrativas e disseminam outras perspectivas sociais, normalmente invisibilizadas pelo cânone. Desse modo, as questões raciais e de gênero têm notoriedade na literatura de Evaristo, apontando para a discussão contemporânea, relevante para os Estudos Culturais, em torno do binômio histórias locais e histórias globais, em que a predominância dessas reitera um enclausuramento ou apagamento daquelas.

Consideramos, então, que a autora mineira questiona essas clausuras, na medida em que traz à tona uma herança histórica e pessoal, marcada por dominações concretas e simbólicas, ressignificando-a e fazendo emergir outras experiências e novos contextos. Nesse sentido, é possível assumir que o lugar de fala de Conceição Evaristo também é a Améfrica (Gonzalez, 1988), termo baseado na categoria político-cultural da "amefricanidade", de base democrática, que "incorpora todo um processo histórico de intensa dinâmica cultural (adaptação, resistência, reinterpretação e criação de novas formas)" (Gonzalez, 1988, p. 76). Falar em Améfrica, portanto, é uma forma de resistência à violência do racismo e ao silenciamento, práticas que desvaneceram a contribuição dos negros da América para o suposto "avanço da humanidade nos níveis filosófico, científico, artístico e religioso" (Gonzalez, 1988, p. 77).

O "escreviver" da autora, a partir de um trabalho com a memória e com a tradição oral, retoma os laços com uma ancestralidade africana e, ao mesmo tempo, por meio de uma dicção consciente e comprometida, faz emergir problemáticas do contemporâneo, mas com raízes históricas, como as desigualdades sociais, raciais e as relações de poder. Conceição Evaristo, ao imprimir seu nome próprio e firmar uma assinatura na cena da literatura brasileira, faz reverberar uma voz autoral que é, ao mesmo 
tempo, coletiva e política, e nos conduz a questionar em que medida somos o outro, ideologicamente formatado por uma cultura cujos lugares de enunciação - brancos, masculinos, canônicos etc. - sempre foram marcados por interesses, valores, identificações centralizados e sobrelevados em detrimento de outras histórias.

\section{Referências}

BENTO, Maria Aparecida Silva (2014). Branqueamento e branquitude no Brasil. In: CARONE, Iray; BENTO, Maria Aparecida Silva (Org.). Psicologia social do racismo: estudos sobre branquitude e branqueamento no Brasil. 6. ed. Petrópolis: Vozes. p. 25-57.

DALCASTAGNÈ, Regina (2008). Entre silêncios e estereótipos: relações raciais na literatura brasileira contemporânea. Estudos de literatura brasileira contemporânea, v. 31, p. 87-110. Disponível em: <https://goo.gl/mc6Bxp>. Acesso em: 20 out. 2016.

ESCOSTEGUY, Ana Carolina (2010). Cartografias dos estudos culturais: uma versão latino-americana. Belo Horizonte: Autêntica. p. 17-64. Disponível em: <https://goo.gl/xiD13M>. Acesso em: 22 jul. 2016.

EVARISTO, Conceição (2007). Da grafia-desenho de minha mãe, um dos lugares de nascimento de minha escrita. In: ALEXANDRE, Marcos Antônio (Org.). Representações performáticas brasileiras: teórias, práticas e suas interfaces. Belo Horizonte: Mazza. p 16-21. Reproduzido no blog pessoal da autora. Disponível em: <https://goo.gl/pYWg1V>. Acesso em: 19 out. 2016.

EVARISTO, Conceição (2016). Histórias de leves enganos e parecenças. Rio de Janeiro: Malê, 2016.

GILROY, Paul (2001). O Atlântico negro como contracultura da modernidade. In: GILROY, Paul. O Atlântico negro: modernidade e dupla consciência. Tradução de Cid Knipel Moreira. São Paulo: 34. p. 33-100.

GONZALEZ, Lélia (1988). A categoria político-cultural de amefricanidade. Tempo Brasileiro, Rio de Janeiro, n. 92/93, p. 69-81.

HALL, Stuart (1997). A centralidade da cultura: notas sobre as revoluções culturais do nosso tempo. Educação e Realidade, Porto Alegre, v. 22, n. 2, p. 15-46. Disponível em: <https://goo.gl/nLKGXr>. Acesso em: 20 out. 2016.

HOOKS, Bell (2014). Racismo e feminismo: a questão da responsabilidade. In: HOOKS, Bell. Ain't I a woman: black women and feminism. London: Pluto Press. 
p. 87-113. Tradução livre para a Plataforma Gueto. Disponível em: <https://goo.gl/8GPqg1>. Acesso em: 20 out. 2016.

JESUS, Carolina Maria de (1963). Quarto de despejo. 7. ed. São Paulo: Francisco Alves.

MIGNOLO, Walter (2003). Uma outra língua, um outro pensamento, uma outra lógica. In: MIGNOLO, Walter. Histórias locais/projetos globais: Colonialidade, saberes subalternos e pensamento liminar. Tradução de Solange Oliveira. Belo Horizonte: Editora da UFMG. p. 421-454.

RAMOS, Alberto Guerreiro (1995). Patologia social do “branco" brasileiro. In: RAMOS, Alberto Guerreiro. Introdução crítica à sociologia brasileira. Rio de Janeiro: Editora UFRJ. p. 215-237.

SANTOS, Boaventura de Sousa (2008). A ecologia de saberes. In: SANTOS, Boaventura de Sousa. A gramática do tempo: para uma nova cultura política. 2. ed. São Paulo: Cortez. p. 137-165.

SILVA, Assunção (2016). Prefácio: a fortuna de Conceição. In: EVARISTO, Conceição. Histórias de leves enganos e parecenças. Rio de Janeiro: Malê.

SODRÉ, Muniz (2000). A identidade como valor. In: SODRÉ, Muniz. Claros e escuros: identidade, povo e mídia no Brasil. 2. ed. Petrópolis: Vozes. p. 233-257.

Recebido em 28 de maio de 2017.

Aprovado em 29 de agosto de 2017.

\section{resumo/abstract/resumen}

\section{A cultura do outro em Histórias de leves enganos e parecenças, de Conceição Evaristo}

Nivana Ferreira da Silva

Com base nos estudos culturais, especificamente nos debates relacionados às formas como a cultura considerada hegemônica se configurou como tal, este artigo propõe uma discussão em torno da constituição do cânone literário, considerando o que este deixa à margem, sobretudo em relação às questões raciais e de gênero. Nesse sentido, consideramos exemplar a literatura de autoria negra e feminina para esta reflexão e debruçamo-nos sobre o trabalho da escritora Conceição Evaristo, a partir do seu livro Histórias de leves enganos e parecenças (2016), objeto cultural emblemático para a problematização apresentada.

Palavras-chave: estudos culturais, cânone literário, Conceição Evaristo. 
The other's culture in Histórias de leves enganos e parecenças, by Conceição Evaristo

Nivana Ferreira da Silva

Based on cultural studies, specifically on debates related to how hegemonic culture has been configured as such, this paper presents a discussion regarding the constitution of the literary canon, taking into account what it marginalizes, mainly in regards to works dealing with race and gender. Thus, we consider black and feminine literature as exemplary for our reflection. We analyze Conceição Evaristo's texts, from her book Histórias de leves enganos e parecenças (2016), as cultural objects that are emblematic to the discussion at hand.

Keywords: Cultural Studies, literary canon, Conceição Evaristo.

\section{La cultura del otro en Histórias de leves enganos e parecenças, de Conceição Evaristo}

Nivana Ferreira da Silva

Con base en los estudios culturales, específicamente en los debates relacionados a las formas como la cultura considerada hegemónica se configuró como tal, este artículo trae una discusión en torno a la constitución del canon literario, teniendo en cuenta lo que es dejado al margen de éste, especialmente en relación a las cuestiones raciales y de género. En ese sentido, consideramos ejemplar para nuestra reflexión la literatura de autoría negra y femenina, y analizamos el trabajo de Conceição Evaristo, a partir de su libro Histórias de leves enganos e pareenças (2016), objeto cultural emblemático para la problematización presentada.

Palabras clave: Estudios Culturales, canon literario, Conceição Evaristo. 